\title{
Influence of Seasonality on the Interaction of Mercury with Aquatic Humic Substances Extracted from the Middle Negro River Basin (Amazon)
}

\author{
Luciana C. de Oliveira, ${ }^{*}, a$ Wander G. Botero, ${ }^{b}$ Felipe A. Santos, ${ }^{c}$ Ézio Sargentini Jr., ${ }^{d}$ \\ Julio C. Rocha and Ademir dos Santos ${ }^{e}$
}

${ }^{a}$ Federal University of São Carlos (UFSCar), 18052-780 Sorocaba-SP, Brazil

${ }^{b}$ Federal University of Alagoas (UFAL), 57309-005 Arapiraca-AL, Brazil

'Institute of Biosciences, São Paulo State University (UNESP), 18618-000 Botucatu-SP, Brazil

${ }^{d N a t i o n a l ~ A m a z o n ~ R e s e a r c h ~ I n s t i t u t e ~(I N P A), ~ 69060-001 ~ M a n a u s-A M, ~ B r a z i l ~}$

eInstitute of Chemistry of Araraquara, São Paulo State University (UNESP), 14800-900 Araraquara-SP, Brazil

\begin{abstract}
As elevadas concentrações de mercúrio em diferentes matrizes ambientais na Amazônia têm sido atribuídas a atividades mineradoras. Entretanto, altas concentrações de mercúrio também estão presentes no solo e na água em locais como a Bacia do médio Rio Negro, distantes de fontes emissoras antropogênicas. A região Amazônica é caracterizada por dois diferentes regimes sazonais, bem definidos em períodos de cheias e vazantes. O objetivo deste trabalho foi investigar as influências sazonais na interação entre mercúrio e substâncias húmicas aquáticas (AHS), que são os principais complexantes orgânicos naturais. Os resultados obtidos por análise estatística multivariada dos dados mostraram que as substâncias húmicas possuem diferentes características estruturais, dependendo do período sazonal. A capacidade das substâncias húmicas em formar complexos com $\mathrm{Hg}$ (II) não está diretamente relacionada ao seu teor de carbono, mas sim à natureza e disponibilidade dos grupos funcionais presentes em sua estrutura. Os grupos funcionais carboxílicos e aromáticos estão diretamente relacionados à maior capacidade de complexação de AHS por íons mercúrio.
\end{abstract}

High mercury concentrations in different environmental matrices in the Amazon have been attributed to mining activities. However, high concentrations of mercury are also present in the soil and water in places like in the middle of the Negro River Basin, which is far away from any anthropogenic emission sources. The Amazon region is characterized by two different regional seasons, with well-defined flood and low water periods. The objective of this work was to investigate the seasonal influences of the interaction between mercury and aquatic humic substances (AHS), which are the main agents of the natural organic complexation capacity. The results of the multivariate statistical analysis of the data showed that the humic substances had different structural characteristics, depending on each season. The ability of humic substances to form complexes with $\mathrm{Hg}(\mathrm{II})$ is not directly related to their carbon content, but to the nature and availability of the functional groups present in its structure. The functional groups are carboxylic and aromatic directly related to the higher complexation capacity of AHS by mercury ions.

Keywords: aquatic humic substances, seasonality, Negro River Basin, Amazonia, mercury

\section{Introduction}

Although the Negro River Basin is distant from anthropogenic emission sources, elevated mercury concentrations have been found in a variety of environmental

*e-mail: 1camargo@ufscar.br matrices in this region of Amazonia. There are indications that this mercury derives from the weathering of rocks, with leaching through soils being the main means of its transport to aquatic systems. ${ }^{1}$

The Negro River, one of the principal tributaries of the Amazon, contains high levels of organic matter (OM), and since the biogeochemical cycling of mercury 
includes the involvement of OM, the river can contain high concentrations of the metal. ${ }^{2}$ The nature of $\mathrm{OM}$ is influenced by the alternating flood and low water regime, ${ }^{3}$ and its interaction with mercury influences the biogeochemical cycle of the metal in terms of its transport, speciation, solubility and bioavailability. ${ }^{1,2,4,5}$

An important characteristic of the biogeochemical cycle of mercury is the variety of routes that it can take in the environment, including its release at the soil/atmosphere and water/atmosphere interfaces, atmospheric transport, and deposition to soil and water surfaces. In contact with soils and sediments, sorption of mercury in insoluble form may be followed by methylation/ demethylation. The cycle is completed by the incorporation of mercury species in precipitation, bioconversion into volatile and soluble forms, release to the atmosphere or bioaccumulation in aquatic organisms. ${ }^{6-8}$

The toxicity of mercury is one of the main reasons for scientific investigation of its behavior. In the Amazon region, Branches et al. ${ }^{9}$ identified symptoms such as vertigo, palpitations, headaches and trembling in patients exposed to mercury vapor. From an epidemiological perspective, the main concern is exposure of riverside communities to organomercury compounds such as methylmercury. The clinical consequences of human exposure to methylmercury and other organomercury compounds are potentially serious, and include neurological effects that can be irreversible. Due to its affinity for adipose tissues, methylmercury tends to bioaccumulate faster than other mercury species.

Complexation with organic matter limits the availability of mercury to the microorganisms responsible for the methylation, and therefore also reduces the bioaccumulation of methylmercury. The main components of the organic matter present in soil, sediments and waters are humic substances (HS), which are refractory materials that have an undefined composition. The apparently large molecular size of humic substances is actually a supramolecular structure of small bio-organic molecules of a molecular mass smaller than $1000 \mathrm{Da}$, held together by weak forces, such the Van der Waals force. ${ }^{10,11}$ Most of the environmental reactivity of HS is controlled by the content of acidic functional groups and their position in the conformational structures of those substances. ${ }^{12}$ Although the characteristics and properties of these substances have been studied for 200 years, the interest in aquatic humic substances (AHS) has intensified over the last 30-40 years due to the greater importance in the awareness of the chemical quality of water destined for human consumption. Hence, studies of the HS properties related to the transportation, liability and complexation of metal species in aquatic systems are essential in order to better understand the behavior of these species in the environment. ${ }^{13}$

The strength and nature of bonding between AHS and metals are directly influenced by the molecular size of AHS, whose molar masses can vary between $<5$ and $>100 \mathrm{kDa}$. Molecular size fractionation procedures can be used to reduce the polydispersion of AHS to obtain distinct fractions possessing similar properties and to enable the characterization of their interactions between metal species. ${ }^{14}$ In order to elucidate the dynamics of mercury in the middle Negro River Basin (Amazon), a project was developed and supported by FAPESP (São Paulo Research Foundation, Brazil), with the objective to propose the biogeochemical cycle of mercury in the region. Since there are many factors that can contribute to the mobility of mercury in the environment, this study aimed to achieve broader conclusions and to investigate the interaction between AHS, major organic complexation in the environment, and mercury considering the seasonal influence in this process.

\section{Experimental}

\section{Reagents}

Analytical grade reagents (suprapur, Merck AG) were used, and the solutions were prepared using deionized water (Milli-Q, Millipore).

\section{Water sample collection}

Collection of water samples was undertaken on a monthly basis over a period of one year in order to explore the influence of seasonality on the structural characteristics and behavior of AHS in the Amazonian environment. The water sample collection points were situated on the left hand bank of the Negro River, between the Tarumã Mirim River and the Tarumã Açu River tributaries, approximately $20 \mathrm{~km}$ west of the Manaus City (GPS: 3 02’ 22S 60 08’21W).

Extraction of the aquatic humic substances using XAD-8 resin

XAD-8 macro-porous resin used to extract AHS was previously purified by successive processing with hydrochloric acid $\left(0.50 \mathrm{~mol} \mathrm{~L}^{-1}\right)$, sodium hydroxide $\left(0.50 \mathrm{~mol} \mathrm{~L}^{-1}\right)$ and methanol ( $24 \mathrm{~h}$ for each process). The procedure most used by researchers of the area in accordance with the International Humic Substances Society (IHSS) ${ }^{15}$ was used for extraction. The samples were filtered under vacuum using Whatman No. 42 filter papers, acidified with 
$6.0 \mathrm{~mol} \mathrm{~L}^{-1}$ hydrochloric acid solution until a $\mathrm{pH}$ value of 3.0 was obtained, and percolated under gravity at a flow

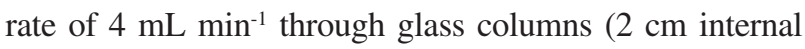
diameter and $25 \mathrm{~cm}$ tall) packed with XAD-8 resin. After saturation indicated by darkening of the resin, a volume of $10 \mathrm{~mL}$ of $0.01 \mathrm{~mol} \mathrm{~L}^{-1}$ hydrochloric acid was used to remove impurities, and the columns were then eluted with $0.10 \mathrm{~mol} \mathrm{~L}^{-1}$ sodium hydroxide at a flow rate of $1.2 \mathrm{~mL} \mathrm{~min}^{-1}$. After the first elution, the resin was purified and the process repeated. The $\mathrm{pH}$ value of the final humic extract was adjusted to 5.0 (a pH similar to that of the Negro River water samples) using $0.10 \mathrm{~mol} \mathrm{~L}^{-1}$ hydrochloric acid.

\section{Purification of the humic extract}

Seamless dialysis membranes were prepared according to the procedure described by Town and Powell. ${ }^{16}$ After treatment for $10 \mathrm{~min}$ each in a $2 \%$ solution of sodium bicarbonate and a $0.01 \mathrm{~mol} \mathrm{~L}^{-1}$ solution of EDTA (ethylenediaminetetraacetic acid) dissodium salt dihydrate, the membranes were washed with deionized water at $65^{\circ} \mathrm{C}$ and refrigerated at ca. $4{ }^{\circ} \mathrm{C}$. The humic extract was concentrated using a rotary evaporator, and purified against deionized water using the dialysis membrane until it tested negative for chlorides (using $0.10 \mathrm{~mol} \mathrm{~L}^{-1}$ silver nitrate solution). After removing the excess of dissolved salts by dialysis, the humic extract was lyophilized according to the procedure described by Vigneault et al. ${ }^{17}$ and the material was then stored in petri dishes in a desiccator.

Nuclear magnetic resonance $\left({ }^{13} \mathrm{C}\right.$ NMR)

${ }^{13} \mathrm{C}$ NMR experiments with cross polarization (CP), magic angle rotation (MAS) and variable amplitude (VA) were done in a Varian Spectrometer (Unity Inova 400 model). The samples were conditioned in a cylindrical zirconium rotor, which was $5 \mathrm{~mm}$ in diameter (Doty Supersonic) and, rotated at $6 \mathrm{KHz}$ in a Doty Supersonic probe to make the solid samples. The VACP/MAS ${ }^{13} \mathrm{C}$ NMR spectra were obtained under the following experimental conditions: a resonance frequency of $100 \mathrm{MHz}$ for ${ }^{13} \mathrm{C}$, a spectral band of $20 \mathrm{KHz}$, a proton preparation pulse of $3.8 \mu \mathrm{s}$, a contact time of $1 \mathrm{~ms}$, an acquisition time of $12.8 \mathrm{~ms}$ and an interval of $500 \mathrm{~ms}$. Hexamethilbenzene (HMB) was used as a reference of the chemical shift in the spectra.

Digestion of the AHS samples and the determination of mercury

A volume of $5.0 \mathrm{~mL}$ of $30 \%$ hydrogen peroxide solution was slowly added to $0.20 \mathrm{~g}$ of AHS, under agitation.
When the sample was completely dissolved, $15.0 \mathrm{~mL}$ of sulfonitric acid solution were slowly added, using an ice bath. The solution was heated for $1 \mathrm{~h}$ at a temperature of $70{ }^{\circ} \mathrm{C}$, cooled to room temperature, and $10.0 \mathrm{~mL}$ of potassium permanganate $(7.5 \%, \mathrm{~m} / \mathrm{v})$ were added. After $15 \mathrm{~min}$, a volume of $5.0 \mathrm{~mL}$ of potassium persulfate $(8 \%, \mathrm{~m} / \mathrm{v})$ was added. The solutions containing the AHS samples were heated for $2 \mathrm{~h}$ at $70{ }^{\circ} \mathrm{C}$, and then left to rest for $12 \mathrm{~h}$. Sufficient hydroxylamine chloride solution $(12 \%, \mathrm{~m} / \mathrm{v})$ was added to reduce the remaining potassium permanganate, and mercury determinations were performed shortly thereafter, using atomic absorption spectrometry, Analyst 300-Perkin Elmer, with cold vapor generation. ${ }^{2,18}$

Fractionation of AHS extracted from the water samples

AHS fractionation was performed as described by Sargentini Jr. et al., ${ }^{14} 250 \mathrm{~mL}$ of AHS $\left(1.0 \mathrm{mg} \mathrm{mL}{ }^{-1}\right.$, $\mathrm{pH}$ 5.0) were pumped through the sequential system for fractionation by ultrafiltration (SSFU), with collection of the following molecular size fractions: $>100 \mathrm{kD}\left(\mathrm{F}_{1}\right), 50-100 \mathrm{kD}$ $\left(\mathrm{F}_{2}\right), 30-50 \mathrm{kD}\left(\mathrm{F}_{3}\right), 10-30 \mathrm{kD}\left(\mathrm{F}_{4}\right), 5-10 \mathrm{kD}\left(\mathrm{F}_{5}\right)$ and $<5 \mathrm{kD}\left(\mathrm{F}_{6}\right)$.

\section{Determination of total organic carbon (TOC)}

Measurements were made using the catalytic combustion technique with infrared detection (Shimadzu TOC-5000 Analyzer), in an oxygen atmosphere. The white limit detection $(3 \sigma)$ of the technique was $0.1 \mathrm{mg} \mathrm{L}^{-1}$ TOC.

Determination of the complexation capacities of dissolved organic matter and AHS for $\mathrm{Hg}(\mathrm{II})$ ions

The analytical procedure proposed by Burba et al. ${ }^{19}$ and adaptated by Pantano et al. ${ }^{20}$ and Serudo et al..$^{13}$ was used to determine the complexation capacities of the various AHS fractions for $\mathrm{Hg}$ (II) ions (Figure 1). This technique is based on a tangential ultrafiltration system (Sartorius Ultrasart X), fitted with a $1 \mathrm{kDa}$ cellulose membrane to prevent passage of humic substances and HS-metal complexes having molecular sizes greater than $1 \mathrm{kDa}$. The membrane allows passage of free metal ions that are not either complexed with HS, or that have been exchanged. Prior to addition of the mercury solution, the membrane was conditioned by pumping AHS solution $(250 \mathrm{~mL})$ through it for around $5 \mathrm{~min}$. The first aliquot $(2 \mathrm{~mL})$ was then filtered, corresponding to time zero (i.e., prior to addition of the mercury solution). $2 \mathrm{~mL}$ volumes of a solution of $1 \mathrm{mg} \mathrm{L}^{-1} \mathrm{Hg}$ (II) in $1 \%$ (v/v) nitric acid were added to the AHS solutions. $2 \mathrm{~mL}$ aliquots of the solution fractions containing $\mathrm{Hg}(\mathrm{II})$ ions isolated by the filtration 
procedure were collected following establishment of equilibrium, which was reached after 15 min under constant agitation. Bromine chloride solutions were added to the filtrates to fix $\mathrm{Hg}^{2+}$ and prevent any losses. Hydroxylamine chlorohydrate $(12 \%, \mathrm{~m} / \mathrm{v})$ was added about 5 min before analysis using cold vapor atomic absorption spectroscopy. A flask containing potassium permanganate was connected to the system in order to capture and to subsequently quantify any reduced mercury present (Figure 1).

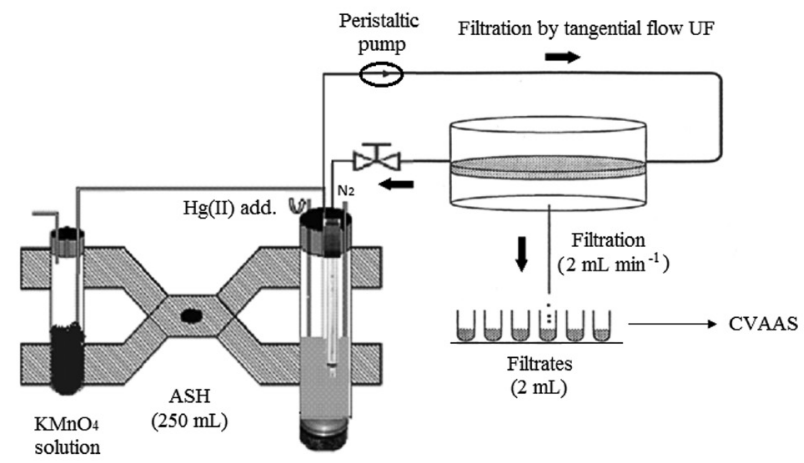

Figure 1. Scheme of the system used to determine the complexation capacity for $\mathrm{Hg}$ (II) ions of aquatic humic substances extracted from samples collected at the Negro River. Conditions: Sartorius Ultrasart $\mathrm{X}$ ultrafiltration system fitted with $47 \mathrm{~mm}$ diameter, $1 \mathrm{kDa}$ porosity, cellulose membrane (Gelman Pall-Filtron OMEGA), AHS solution $\mathrm{pH}$ 6.0 , and solution of $0.024 \%(\mathrm{~m} / \mathrm{v})$ potassium permanganate in $4 \%(\mathrm{v} / \mathrm{v})$ sulfuric acid solution.

\section{Results and Discussion}

Seasonal flooding in the middle Negro River Basin increases the river level by $8-10 \mathrm{~m}$, and for the study period the peak and lowest water levels occurred in July and November 2002, respectively (Figure 2).

Characterization of AHS extracted from the water samples, which were monthly collected revealed seasonal differences in their molecular structures. ${ }^{2}$ Statistical analysis was used to classify AHS into three groups according to the degree of humification, which corresponded to the periods in which they were collected: March-May 2002, June-October 2002 and November 2002-February 2003. One sample of AHS from each group was selected for molecular size fractionation and analysis of the carbon content distribution and complexation capacity for mercury ions. The samples selected for fractionation were those collected in March, July and December 2002. According to Thurman, ${ }^{21}$ around $50 \%$ of the dissolved organic carbon comprises fulvic and humic acids, with aquatic humic substances generally consisting of $90 \%$ fulvic acids and $10 \%$ humic acids.

Significant differences between the samples collected during both the high and low water periods were observed

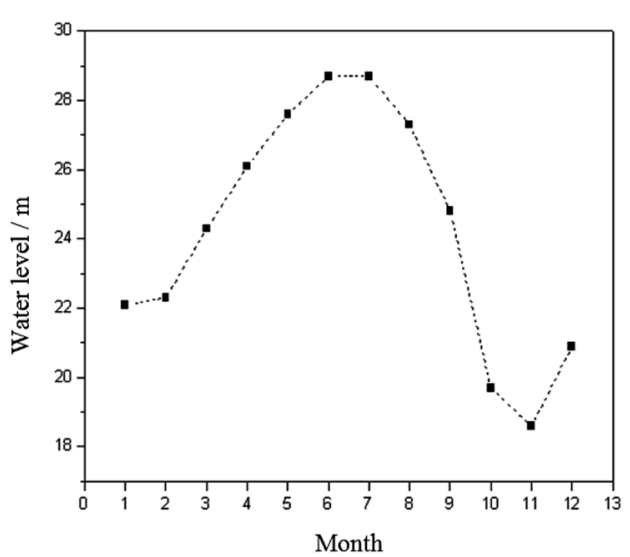

Figure 2. Monthly mean water levels of the Negro River (source: National Institute for Amazonian Research (INPA)).

for both carbon distributions and the complexation capacities of the different AHS molecular size fractions (Figure 3). In the case of AHS from the March 2002 sample, approximately $65 \%$ of the carbon content was equally distributed between the fractions $\mathrm{F}_{1}$ and $\mathrm{F}_{6}$. For the July 2002 sample, $F_{1}(>100 \mathrm{kDa})$ showed the highest carbon content, with reduced amounts in $\mathrm{F}_{2}$ and $\mathrm{F}_{5}$. In this situation, the total amount of carbon in fractions $\mathrm{F}_{1}, \mathrm{~F}_{2}$ and $\mathrm{F}_{3}$ was approximately $78 \%$, indicating a predominance of carbon in the first fractions.

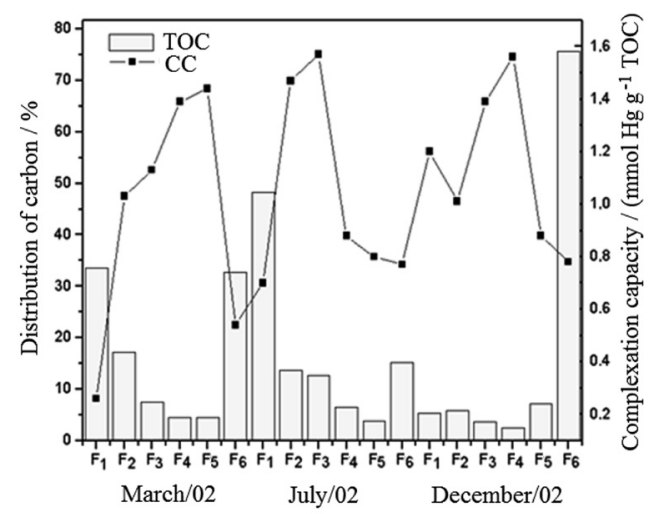

Figure 3. Carbon content distribution and complexation capacity for $\mathrm{Hg}$ (II) ions of the different molecular size humic fractions extracted from water samples, collected from the Negro River in March, July and December 2002 and fractionated using multiple stage tangential flow sequential ultrafiltration.

According to Guetzloff and Rice, ${ }^{22}$ humic acid and fulvic acid isolated from the same environment are composed of molecules having distinct sizes, which are larger for humic acid and smaller for fulvic acid. This is also reflected in the molecular size interval of aquatic particles. It can therefore be inferred that the July 2002 sample contained more larger molecules (humic acid), and since AHS are typically composed of $90 \%$ fulvic acids and $10 \%$ humic acids, during this period there was a large influence 
of organic soil matter, in agreement with the higher river level during this period and the typically alloctone origin of humic substances found in rivers and creeks, deriving from soil and organic plant matter. ${ }^{21}$ These results are in agreement with the ones obtained by Bisinoti et al. ${ }^{6}$ indicating that the increase of fresh $\mathrm{OM}$ associated with the increase in the water level causes a major change in the water chemistry of Amazonian black waters.

From Figure 3, it can be seen that for HS extracted from water collected in December 2002, fraction $\mathrm{F}_{6}$ contained about $75 \%$ of the total carbon content, showing that this sample preferentially contained smaller molecules.

A seasonal influence on AHS is evident from the distribution of carbon in the different fractions obtained by sequential fractionation. Table 1 lists, in decreasing order, the total organic carbon contents and the complexation capacities of the different AHS size fractions extracted from samples collected in March, July and December 2002. From the carbon distributions, it can be seen that the highest carbon contents were in fractions $F_{1}$ and $F_{6}$ from the March sample. For the July and December samples, fractions $\mathrm{F}_{1}$ and $\mathrm{F}_{6}$ contained most carbon, respectively. For the March sample, the same fractions $\left(F_{1}\right.$ and $\left.F_{6}\right)$ showed the lowest $\mathrm{Hg}(\mathrm{II})$ complexation capacity. Although the $\mathrm{F}_{1}$ and $\mathrm{F}_{6}$ fractions probably contained larger and smaller molecules, respectively, their complexation capacities were similar, which could be related to the conformation adopted by the molecules, leading to a molecular arrangement that influenced their complex similarly in both cases. For July, the lowest complexation capacity was observed in $F_{1}$, while for December $F_{6}$ and $F_{4}$ showed the lowest and highest complexation capacities, respectively. For this group of samples, it can be seen that those showing lower complexation capacities generally had higher carbon contents. Therefore, it can be inferred that the quantity of carbon present in a sample of HS is not proportional to the number of functional groups present.

Environmental studies can generate large quantities of experimental data, and exploratory statistical techniques are useful to correlate variables and assist in the interpretation of results. Hierarchical grouping analysis was used here to examine the seasonal influence on the AHS samples fractionated according to the molecular size. In Figure 4A, the formation of two groups can be seen: (a) pluviometric index and total carbon content and (b) AHS complexation capacity and fluviometric index. In Figure 4B, three main sample groupings can be seen: (a) $F_{1}$ and $F_{6}$ for March and $F_{6}$ for December, (b) $F_{2}, F_{3}, F_{4}$ and $F_{5}$ for March and $F_{1}$, $\mathrm{F}_{2}, \mathrm{~F}_{3}, \mathrm{~F}_{4}$ and $\mathrm{F}_{5}$ for December and (c) $\mathrm{F}_{1}, \mathrm{~F}_{2}, \mathrm{~F}_{3}, \mathrm{~F}_{4}, \mathrm{~F}_{5}$ and $\mathrm{F}_{6}$ for July. Group (a) is essentially composed of fractions showing the lowest complexation capacity and the highest carbon content. In groups (b) and (c), it can be seen that fractions having most similarity were those from the same

(A)

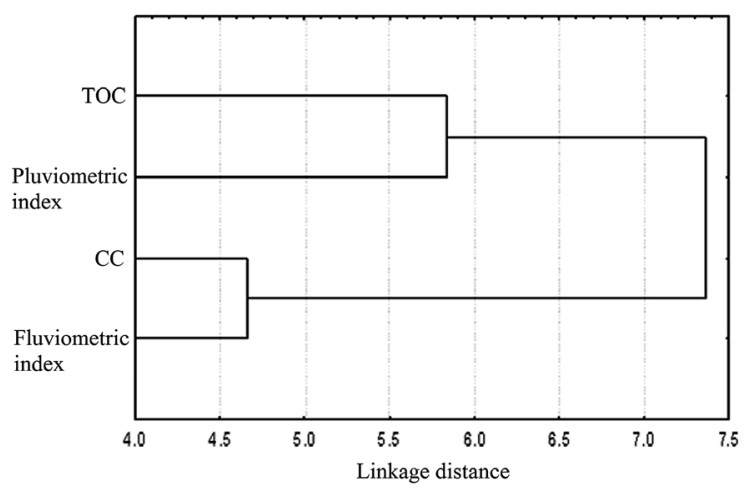

(B)

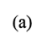

(b)

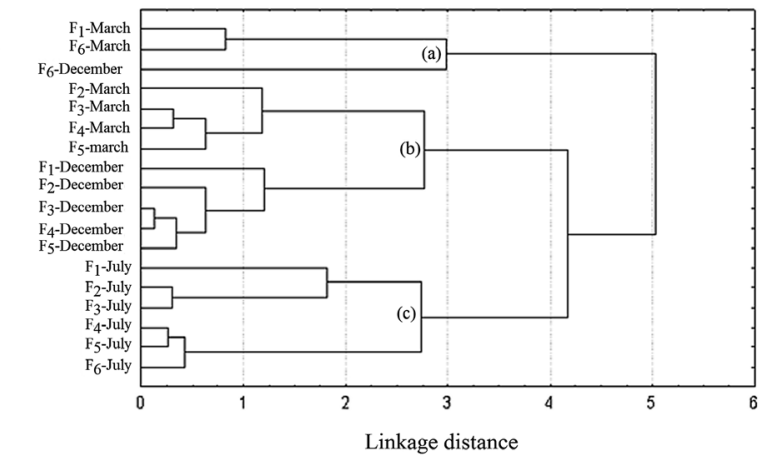

Figure 4. (A) Dendrogram obtained from determinations of the complexation capacities of aquatic humic substances for $\mathrm{Hg}(\mathrm{II})$ ions, total organic carbon contents, and pluviometric and fluviometric indices, and (B) dendrogram for aquatic humic substances extracted from the Negro River water, fractionated according to molecular size: $>100 \mathrm{kDa}\left(\mathrm{F}_{1}\right), 100-50 \mathrm{kDa}\left(\mathrm{F}_{2}\right), 50-30 \mathrm{kDa}\left(\mathrm{F}_{3}\right)$, $30-10 \mathrm{kDa}\left(\mathrm{F}_{4}\right), 10-5 \mathrm{kDa}\left(\mathrm{F}_{5}\right)$ and $<5 \mathrm{kDa}\left(\mathrm{F}_{6}\right)$.

Table 1. Decreasing orders of organic carbon contents and complexation capacities for different molecular size fractions of aquatic humic substances extracted from the Negro River water samples

\begin{tabular}{lll}
\hline Sample & Parameter & Decreasing order \\
\hline July 2002 & total organic carbon & $\mathrm{F}_{1}>\mathrm{F}_{6}>\mathrm{F}_{2}>\mathrm{F}_{3}>\mathrm{F}_{4}>\mathrm{F}_{5}$ \\
& complexation capacity of AHS for Hg(II) ions & $\mathrm{F}_{3}>\mathrm{F}_{2}>\mathrm{F}_{4}>\mathrm{F}_{5}>\mathrm{F}_{6}>\mathrm{F}_{1}$ \\
December 2002 & total organic carbon & $\mathrm{F}_{6}>\mathrm{F}_{5}>\mathrm{F}_{2}>\mathrm{F}_{1}>\mathrm{F}_{3}>\mathrm{F}_{4}$ \\
& complexation capacity of AHS for Hg(II) ions & $\mathrm{F}_{4}>\mathrm{F}_{3}>\mathrm{F}_{1}>\mathrm{F}_{2}>\mathrm{F}_{5}>\mathrm{F}_{6}$ \\
March 2002 & total organic carbon & $\mathrm{F}_{1}>\mathrm{F}_{6}>\mathrm{F}_{2}>\mathrm{F}_{3}>\mathrm{F}_{4} \approx \mathrm{F}_{5}$ \\
& complexation capacity of AHS for Hg(II) ions & $\mathrm{F}_{5}>\mathrm{F}_{4}>\mathrm{F}_{3}>\mathrm{F}_{2}>\mathrm{F}_{6}>\mathrm{F}_{1}$ \\
\hline
\end{tabular}


Table 2. Peak assignments for the ${ }^{13} \mathrm{C}$ NMR spectra of the aquatic humic substances extracted from the Negro River and their integrated areas (\%)

\begin{tabular}{|c|c|c|c|c|c|c|c|c|c|}
\hline \multirow[b]{2}{*}{ Sample } & \multicolumn{5}{|c|}{ Integration / \% } & \multirow[b]{2}{*}{$\mathrm{HI}$} & \multirow[b]{2}{*}{ HB } & \multirow[b]{2}{*}{$\mathrm{HI} / \mathrm{HB}$} & \multirow{2}{*}{$\begin{array}{l}\mathrm{Hg}(\mathrm{II}) \\
\left(\mu \mathrm{g} \mathrm{g}^{-1}\right)\end{array}$} \\
\hline & $\begin{array}{c}0-45 \mathrm{ppm} \\
\text { aliphatic }\end{array}$ & $\begin{array}{l}45-65 \mathrm{ppm} \\
\mathrm{C}-\mathrm{O}, \mathrm{C}-\mathrm{N}\end{array}$ & $\begin{array}{l}65-90 \text { ppm } \\
\text { O-aliphatic }\end{array}$ & $\begin{array}{c}90-155 \mathrm{ppm} \\
\text { aromatic }\end{array}$ & $\begin{array}{c}155-190 \mathrm{pm} \\
\text { carboxil }\end{array}$ & & & & \\
\hline March 2002 & 50.1 & 3.0 & 17.1 & 9.3 & 9.6 & 59.4 & 29.7 & 2.0 & 8.24 \\
\hline December 2002 & 34.3 & 2.6 & 28.7 & 19.8 & 10.1 & 54.1 & 41.4 & 1.3 & 35.32 \\
\hline July 2002 & 45.1 & 2.8 & 24.3 & 9.2 & 9.3 & 54.3 & 36.4 & 1.5 & 6.70 \\
\hline
\end{tabular}

month. Therefore, there was distinction according to the seasons, but not according to molecular size. Due to the flood/low water regime of the Amazon basin, the seasonal factor appears to be predominant in influencing the nature of AHS characterized according to the molecular size.

The complexation capacities of AHS for $\mathrm{Hg}$ (II) ions were determined in the original samples, before making any fractionation. The values obtained were: $1.74 \mathrm{mmol}$ of $\mathrm{Hg} \mathrm{g}^{-1}$ of TOC in December, $0.85 \mathrm{mmol}$ of $\mathrm{Hg} \mathrm{g}^{-1}$ of TOC in July and $1.04 \mathrm{mmol}$ of $\mathrm{Hg} \mathrm{g}^{-1}$ of TOC in March. Therefore, it is apparent that during the flood period (in July) the AHS complexation capacity was lower, while during the low water period it was higher.

Studies proposed by Serudo et al. ${ }^{13}$ and Bisinoti et al. ${ }^{23}$ mentioning that in soils from this region, the highest complexing capacity of soil humic substances (SHS) occurred in flooded soils. These results suggest that there may be a competition between AHS and SHS during the flood periods. Thus, the full period of the SHS complex with a higher concentration of mercury, being a lower mercury concentration in the environment available to complex with the AHS.

To further clarify the interaction between mercury and AHS, it was made of the correlation results of complexation with ${ }^{13} \mathrm{C}$ NMR data of AHS to verify the functional group which will be the primarily responsible for the complexation of mercury ions.

The calculation of the percentages of carbon groups in the structures of HS was made based on the following chemical shifts: 0-45 ppm: aliphatic carbons, 45-65 ppm: $\mathrm{C}-\mathrm{O}$ and $\mathrm{C}-\mathrm{N}$ groups; 65-90 ppm: $\mathrm{O}-$ aliphatic carbons, 90-155 ppm: aromatic carbons and 155-190 ppm: carboxylic carbon. ${ }^{24}$ The percentages obtained for the aliphatic carbons and aromatic carbons were assigned to hydrophobic, while the groups $\mathrm{C}-\mathrm{O}, \mathrm{C}-\mathrm{N}, \mathrm{O}-\mathrm{alkyl}$ and carboxylic assigned the hydrophilic carbon. Thus, the percentages of carbon-carbon non-polar and polar were used to calculate the hydrophobic index (HB) and hydrophilic index (HI), respectively (Table 2). ${ }^{24}$

The HI/HB ratio provides an estimate of the capacity of HS compounds interacting with different polarities.
High HI/HB ratio represents a higher affinity interaction of humic compounds with higher polarity. ${ }^{24}$ Thus, the AHS sample extracted from water samples collected in March is classified as more hydrophilic. The December sample can be classified as more hydrophobic. According to the mercury contents quantified in three samples, it is noted that the December sample quantity of mercury has a much higher than the other two, it can be inferred a directly proportional relation between hydrophobicity and mercury ions present in the AHS samples.

According to the linear relationship obtained from the Pearson correlation between data and ${ }^{13} \mathrm{C}$ RMN complexation of HS by mercury ions (Table 3), it can be seen that the aromatic carboxylic groups are strongly correlated with the ability of complex mercury, corroborating data literature. ${ }^{23-25}$ The ratio of carboxylic groups is possibly due to the fact that these groups are the most oxidated and therefore related to the most refractory OM. In literature, ${ }^{13,18}$ some authors have examined the relation between the complexing ability of metal species and degree of humification of OM, that is, the greater the degree of humification, the greater complexing ability of certain metal species. In general, the study of the relationship between AHS functional groups determined by ${ }^{13} \mathrm{C}$ NMR may indicate which of the samples is more efficient for the complexation of metal species influencing its availability in the environment.

The results of these studies led to a widespread tendency in changing the structural characteristics of AHS

Table 3. Parameters of correlation between the ${ }^{13} \mathrm{C}$ NMR data and the complexation capacities of the humic substances by mercury ions

\begin{tabular}{lccc}
\hline \multirow{2}{*}{ Group } & \multicolumn{3}{c}{ Linear parameter } \\
\cline { 2 - 4 } & $\mathrm{ax}$ & $\mathrm{b}$ & $\mathrm{R}^{2}$ \\
\hline Aliphatic (0-45 ppm) & -0.0504 & 3.386 & 0.754 \\
C-O; C-N (45-65 ppm) & -1.75 & 6.11 & 0.558 \\
O-Aliphatic (65-90 ppm) & 0.0518 & -0.0015 & 0.4196 \\
Aromatic (90-155 ppm) & 0.0755 & 0.2464 & 0.9621 \\
Carboxil (155-190 ppm) & 1.1418 & -9.8278 & 0.9693 \\
\hline
\end{tabular}

$\mathrm{R}^{2}$ : correlation coefficient. 
Table 4. Tendencies for changes in the characteristics of the Negro River aquatic humic substances, as a function of season

\begin{tabular}{lll}
\hline Parameter & Flood & Low water \\
\hline Organic matter & recent & refractory \\
HS molecular size & larger molecules & smaller molecules \\
Total organic carbon & $\begin{array}{l}\text { greater in larger } \\
\text { fractions }\end{array}$ & $\begin{array}{l}\text { greater in smaller } \\
\text { fractions }\end{array}$ \\
$\begin{array}{l}\text { HS complexation } \\
\text { capacity }\end{array}$ & smaller & greater \\
\hline
\end{tabular}

as a seasonal function, including what time of years the largest complexation of mercury because of the structural characteristics of AHS, minimizing the availability of mercury in the environment, directly influencing the cycle mercury in the region studied (Table 4).

\section{Conclusions}

The distribution of carbon in the different AHS size fractions was indicative of significant differences between samples in the structures of the humic substances. In December, the period of low water in the Rio Negro, humic material was preferentially composed of smaller molecules. In July (high water), larger molecules were present, while an intermediate composition was obtained in March. The low water level in December suggests that there was less influence of soil organic matter at this time, in contrast to the July high water period when AHS showed a greater influence of soil organics. These findings demonstrate the influence of seasonality on formation of aquatic humic substances, with the fractionation procedure confirming that AHS were composed of substances having different structures according to season.

The complexation capacity, for $\mathrm{Hg}$ (II) ions, of AHS in different size fractions indicated that, in general, the greater the carbon content, the lower the complexation capacity. It can therefore be inferred that the latter was not directly related to carbon content, but possibly to the type and availability of the functional groups present. Multivariate statistical analyses indicated that the samples could be grouped according to the month of collection and rather than to molecular size.

The results obtained in this study showed that AHS extracted from samples from the middle of the Negro River Basin have a change in the structural characteristics as a seasonal function, directly related to the complex of mercury ions, which shows the importance of this process in the mobility of mercury in the middle of the Negro River basin and the natural cycle of mercury in the Amazon region.

\section{Acknowledgements}

The authors thank FAPESP (Fundação de Amparo à Pesquisa do Estado de São Paulo), CNPq (Conselho Nacional de Desenvolvimento Científico e Tecnológico), CAPES (Coordenação de Aperfeiçoamento de Pessoal de Nível Superior) and FUNDUNESP for financial support and research fellowships.

\section{References}

1. da Silva, G. S.; Bisinoti, M. C.; Fadini, P. S.; Magarelli, G.; Jardim, W. F.; Fostier, A. H.; J. Braz. Chem. Soc. 2009, 20, 1127.

2. Oliveira, L. C.; Sargentini Jr., E.; Rosa, A. H.; Rocha, J. C.; Simões, M. L.; Martin-Neto, L.; da Silva, W. T. L.; Serudo, R. L.; J. Braz. Chem. Soc. 2007, 18, 860.

3. Rodriguez-Zúñiga, U. F.; Milori, D. M. B. P.; Rocha, J. C.; Martin-Neto, L.; da Silva, W. T. L.; Oliveira, L. C.; Environ. Sci. Technol. 2008, 42, 1948.

4. Lacerda, D.; Malm, O.; Estud. Av. 2008, 63, 173.

5. Gu, B.; Bian, Y.; Miller, C. L.; Proceed. Natl. Acad. Sci. U.S.A. 2011, 108, 1479.

6. Bisinoti, M. C.; Jardim, W. F.; Sargentini Jr., E.; J. Braz. Chem. Soc. 2007, 18, 544.

7. Jardim, W. F.; Bisinoti, M. C.; Fadini, P. S.; Silva, G. S.; Aquat. Geochem. 2010, 16, 267.

8. Mousavi, A.; Chávez, R. D.; Ali, A. S.; Cabaniss, S. E.; Environ. Forensics 2011, 12, 14.

9. Branches, F. J. P.; Erickson, T. B.; Aks, S. E.; Hryhorczuk, D. O.; J. Toxicol. Clin. Toxicol. 1993, 31, 295.

10. Piccolo, A.; Advan. Agron. 2002, 75, 57.

11. Sutzkover-Gutman, I.; Hasson, D.; Semiat, R.; Desalination 2010, 261, 218.

12. Maia, C.M.B.F.; Piccolo A.; Mangrich, A. S.; Chemosphere 2008, 73, 1162.

13. Serudo, R. L.; Oliveira, L. C.; Rocha, J. C.; Paterlini, W. C.; Rosa, A. H.; Silva, H. C.; Botero, W. G.; Geoderma 2007, 138, 229.

14. Sargentini Jr., E.; Rocha, J. C.; Rosa, A. H.; Zara, L. F.; Santos, A.; Quím. Nova 2001, 24, 399.

15. http://www.humicsubstances.org/isolation.html accessed in August 2012.

16. Town, R. M.; Powell, H. K. J.; Anal. Chim. Acta 1992, $256,81$.

17. Vigneault, B.; Percot, A.; Lafleur, M.; Campbell, P. G. C.; Environ. Sci. Technol. 2000, 34, 3907.

18. Rocha, J. C.; Santos, A.; Sene, J. J.; Eclética Quím. 1994, 19 , 119.

19. Burba, P.; Van Den Bergh, J.; Klockow, D.; Fresenius J. Anal. Chem. 2001, 371, 660.

20. Pantano, G.; Tadini, A. M.; Bisinoti, M. C.; Moreira, A. B.; dos Santos, A.; de Oliveira, L. C., Martin, C. S.; Org. Geochem. 2011, 43, 156, DOI: 10.1016/j.orggeochem.2011.10.002 
21. Thurman, E. M. In Humic Substances in Soil, Sediment, and Water; Aiken, G. R.; McCarthy, P.; McKnight D.; Wershaw, R., Eds.; John Wiley and Sons: New York, 1985, p. 87-103.

22. Guetzloff, T. F.; Rice, J. A.; Humic and Fulvic Acids: Isolation, Structure, and Environmental Role, $2^{\text {nd }}$ ed.; American Chemical Society: Washington, 1996.

23. Bisinoti, M.; Jardim, W. F.; Rocha, J. C.; Quím. Nova 2005, 28, 3.
24. Piccolo, A.; Conte, P.; Cozzolino, A.; Soil Sci. 2001, 166, 174.

25. Rocha, J. C.; Sargentini Jr., E.; Zara, L. F.; Rosa, A. H.; Santos, A.; Burba, P.; Talanta 2003, 61, 699.

Submitted: May 18, 2012

Published online: September 11, 2012

FAPESP has sponsored the publication of this article. 